\title{
Rumen simulation technique study on the interactions of dietary lauric and myristic acid supplementation in suppressing ruminal methanogenesis
}

\author{
Carla R. Soliva ${ }^{1}$, Leo Meile ${ }^{2}$, Adam Cieślak ${ }^{1,3}$, Michael Kreuzer ${ }^{1}$ and Andrea Machmüller ${ }^{1} \dagger$ \\ ${ }^{1}$ Institute of Animal Science, Animal Nutrition and \\ ${ }^{2}$ Institute of Food Science and Nutrition, Laboratory of Food Biotechnology, Swiss Federal Institute of Technology Zurich, \\ ETH Zentrum/LFW, CH-8092 Zurich, Switzerland \\ ${ }^{3}$ Department of Animal Nutrition and Feed Management, Agricultural University of Poznań, ul. Wolynska 33, \\ 60-637 Poznań, Poland
}

(Received 27 November 2003 - Revised 8 June 2004 - Accepted 29 June 2004)

\begin{abstract}
The interactions of lauric $\left(\mathrm{C}_{12}\right)$ and myristic acid $\left(\mathrm{C}_{14}\right)$ in suppressing ruminal methanogenesis and methanogens were investigated with the rumen simulation technique (Rusitec) using bovine ruminal fluid. The fatty acids were added to basal substrates (grass hay:concentrate, $1: 1.5$ ) at a level of $48 \mathrm{~g} / \mathrm{kg}$ DM, provided in $\mathrm{C}_{12}: \mathrm{C}_{14}$ ratios of 5:0, 4:1, 3:2, 2.5:2.5, 2:3, 1:4 and 0:5. Additionally, an unsupplemented control consisting of the basal substrates only was employed. Incubation periods lasted for $15(n 4)$ and $25(n 2) \mathrm{d}$. $\mathrm{CH}_{4}$ formation was depressed by any fatty acid mixture containing at least $40 \% \mathrm{C}_{12}$, and effects persisted over the complete incubation periods. The greatest depression (70\% relative to control) occurred with a $\mathrm{C}_{12}: \mathrm{C}_{14}$ ratio of $4: 1$, whereas the second most effective treatment in suppressing $\mathrm{CH}_{4}$ production ( $60 \%$ relative to control) was found with a ratio of 3:2. Total methanogenic counts were decreased by those mixtures of $\mathrm{C}_{12}$ and $\mathrm{C}_{14}$ also successful in suppressing methanogenesis, the $4: 1$ treatment being most efficient (60\% decline). With this treatment in particular, the composition of the methanogenic population was altered in such a way that the proportion of Methanococcales increased and Methanobacteriales decreased. Initially, $\mathrm{CH}_{4}$ suppression was associated with a decreased fibre degradation, which, however, was reversed after $10 \mathrm{~d}$ of incubation. The present study demonstrated a clear synergistic effect of mixtures of $\mathrm{C}_{12}$ and $\mathrm{C}_{14}$ in suppressing methanogenesis, mediated probably by direct inhibitory effects of the fatty acids on the methanogens.
\end{abstract}

Methane: Medium-chain fatty acids: Lipids: Rusitec

$\mathrm{CH}_{4}$ is the second most problematic greenhouse gas (Wuebbles \& Hayhoe, 2002) and ruminant livestock are responsible for about $25 \%$ of the total anthropogenic emission of $\mathrm{CH}_{4}$ (Khalil, 2000). Livestock generate $\mathrm{CH}_{4}$ via methanogenic archaea, which inhabit the rumen, i.e. microbes that utilise $\mathrm{H}_{2}$ in order to reduce $\mathrm{CO}_{2}$ (Miller, 1995). Fatty acids have been known to have antimicrobial properties against bacteria, yeasts, tumor cells and viruses for many decades (for example, Ababouch et al. 1992) and the use of dietary fats seems to be an effective method for suppressing ruminal methanogenesis (for example, Jouany, 1994). Among the saturated fatty acids, medium-chain fatty acids (MCFA) have been demonstrated to have the greatest inhibitory effect on ruminal methanogenesis (Blaxter \& Czerkawski, 1966; Dohme et al. 2001a) and ruminal methanogens (Henderson, 1973). In a short-term in vitro study, Soliva et al. (2003b) showed the efficacy of lauric acid $\left(\mathrm{C}_{12}\right)$ in that respect, while myristic acid $\left(\mathrm{C}_{14}\right)$ decreased total counts of archaea but did not alter $\mathrm{CH}_{4}$ formation. However, methanogenesis was decreased with similar dietary proportions of $\mathrm{C}_{14}$ in vitro with the rumen simulation technique (Rusitec) system (46 $\mathrm{g} \mathrm{C}_{14} /$ $\mathrm{kg}$ DM; Dohme et al. 2001a) as well as in vivo (50 g $\mathrm{C}_{14} / \mathrm{kg}$ DM; Machmüller et al. 2003). Soliva et al. (2003b) showed that within $24 \mathrm{~h}$ of incubation some mixtures of $\mathrm{C}_{12}$ and $\mathrm{C}_{14}$ decreased $\mathrm{CH}_{4}$ formation to almost zero as did the supplementation of $\mathrm{C}_{12}$ alone, indicating a synergistic effect between $\mathrm{C}_{12}$ and $\mathrm{C}_{14}$. Koster \& Cramer (1987) noted that mixtures of non-esterified $\mathrm{C}_{12}$ and $\mathrm{C}_{14}$, when added to granular sludge in batch-culture studies, could be even more efficient in suppressing $\mathrm{CH}_{4}$ production than when given alone. A major role of $\mathrm{C}_{14}$ in inhibiting ruminal methanogenesis could therefore be its synergism with $\mathrm{C}_{12}$, which would explain the known

Abbreviations: MCFA, medium-chain fatty acids; NDF, neutral-detergent fibre; OM, organic matter; Rusitec, rumen simulation technique; VFA, volatile fatty acids.

* Corresponding author: Dr Carla R. Soliva, fax +41 1632 1128, email carla.soliva@inw.agrl.ethz.ch

$\dagger$ Present address: AgResearch Ltd., Grasslands Research Centre, Palmerston North, New Zealand. 
efficacy of various feeds containing mixtures of $\mathrm{C}_{12}$ and $\mathrm{C}_{14}$ (Dohme et al. 2000).

The aim of the present investigation was to test, using the Rusitec (Czerkawski \& Breckenridge, 1977), whether synergism of $\mathrm{C}_{12}$ and $\mathrm{C}_{14}$ in suppressing ruminal methanogenesis and methanogens occurs when supplemented to a mixture of grass hay and concentrate. In contrast to previous Rusitec studies, extended fermentation periods of up to $25 \mathrm{~d}$ were chosen. This should allow the development of possible adaptation processes in ruminal fermentation and methanogenesis. Furthermore, the still unclear relationship between the level of ruminal $\mathrm{CH}_{4}$ formation and the numbers of total archaea (Soliva et al. 2003a) was investigated in order to deepen our understanding of the $\mathrm{CH}_{4}$-suppressing effect of MCFA.

\section{Materials and methods}

\section{Experimental protocol: medium-chain fatty acid mixtures and time periods}

The experiment was carried out with an eight-fermenter Rusitec system, modified as described by Machmüller et al. (2002). Seven mixtures with $\mathrm{C}_{12}: \mathrm{C}_{14}$ ratios of 5:0, $2: 1,3: 2,2 \cdot 5: 2 \cdot 5,2: 3,1: 4$ and $0: 5$ were supplemented at $0.7 \mathrm{~g} / \mathrm{d}$ (DM basis) to basal substrates and compared with the unsupplemented basal substrates (Table 1). The purity of the fatty acids was $97 \%$ (Fluka Chemie AG, Buchs, Switzerland). The basal substrates consisted of grass hay and concentrate in a 1:1.5 ratio and were added in portions of $14 \mathrm{~g} \mathrm{DM} / \mathrm{d}$. In order to simulate the chewing activity of the ruminant, the grass hay was minced in a regular food mixer (Moulinette ${ }^{\circledR}$ S; GROUP Moulinex, Paris, France). Barley and soyabean meal, which represented the concentrate, were ground to a diameter of $1 \mathrm{~mm}$. Each dietary treatment was tested in four replicates in subsequent experimental periods lasting for $15 \mathrm{~d}$ each $(n 4)$. The first $5 \mathrm{~d}$ were considered the minimal period necessary to obtain steady-state conditions in the Rusitec system (Czerkawski \& Breckenridge, 1977). The following $10 \mathrm{~d}$

Table 1. Composition of the dietary substrates

\begin{tabular}{lcc}
\hline Basal diet... & Control & MCFA \\
\hline Supply per fermenter (g DM/d) & & \\
Grass hay & 5.73 & 5.73 \\
Concentrate & 8.17 & 8.17 \\
$\quad$ Barley & $5 \cdot 72$ & $5 \cdot 72$ \\
$\quad$ Soyabean meal & 2.45 & 2.45 \\
Mineral-vitamin premix & 0.07 & 0.07 \\
Calcium carbonate & 0.03 & 0.03 \\
Lauric and myristic acid & - & 0.70 \\
Total DM supply & 14.00 & 14.70 \\
Analysed nutrient composition (g/kg DM) & \\
Organic matter & 947 & 949 \\
Diethyl ether extract & 16 & 61 \\
Crude protein & 205 & 196 \\
NDF & 276 & 263 \\
Non-NDF carbohydrates & 450 & 430 \\
\hline
\end{tabular}

MCFA, medium-chain fatty acids; NDF, neutral-detergent fibre. *Contained (per kg): Ca, $140 \mathrm{~g} ; \mathrm{P}, 70 \mathrm{~g} ; \mathrm{Na}, 80 \mathrm{~g} ; \mathrm{Mg}, 30 \mathrm{~g}$; Se, $15 \mathrm{mg}$; vitamin $A, 150 \mathrm{mg}$; vitamin $D_{3}, 3 \mathrm{mg}$; vitamin $\mathrm{E}, 1.67 \mathrm{~g}$. (days 6 to 15 ) were split into two measurement periods for later statistical calculations. The first sub-period (P1; days 6 to 10) complied with the incubation period applied in former Rusitec experiments (for example, Dohme et al. 1999; Abel et al. 2002; Machmüller et al. 2002). The second sub-period ( $\mathrm{P} 2$; days 11 to 15$)$ was a prolongation of the regularly conducted incubation period. P2 not only served as a control for the repeatability of the results but also tested whether adaptation processes to the experimental treatments took place and whether fermentation in the in vitro Rusitec system could be well maintained over a longer period of time. For the latter purpose, two of the four experimental runs were prolonged up to $25 \mathrm{~d}$ during which $\mathrm{pH}, \mathrm{NH}_{3}$, bacterial and protozoal counts, volatile fatty acids (VFA) and fermentation gases were monitored.

\section{Rusitec fermenter set-up}

At the beginning of each experimental run the fermenters (1 litre volume each) were filled with $100 \mathrm{ml}$ pre-warmed buffer solution (artificial saliva; Czerkawski \& Breckenridge, 1977) and $900 \mathrm{ml}$ fermenter fluid. Ruminal fluid was collected from a rumen-fistulated, non-lactating Brown Swiss cow fed a diet consisting of grass hay and concentrate in a ratio of $1 \cdot 5: 1 \cdot 0$. Before incubation, the ruminal fluid was strained through four layers of gauze. On the first day of each experimental run two nylon bags, one filled with solid ruminal content, the other filled with the respective dietary treatment, were put into each fermenter. The nylon bags $(70 \times 140 \mathrm{~mm})$ had a pore size of $100 \mu \mathrm{m}$ as was recommended by Carro et al. (1995). After $24 \mathrm{~h}$ of incubation the system was opened and the bag containing solid ruminal content was replaced by another bag containing the specific dietary treatment. Afterwards, each nylon bag was incubated in the fermenter for $48 \mathrm{~h}$. Anaerobic conditions were re-established in the fermenters by rinsing the system with gaseous $\mathrm{N}_{2}$ for $3 \mathrm{~min}$ (3 litres/min) after the daily supply of substrate was completed. The buffer flow rate was kept at $500 \mathrm{ml} / \mathrm{d}$.

\section{Sampling procedures and analyses}

Samples of fermenter fluid were analysed for $\mathrm{pH}, \mathrm{NH}_{3}$ and redox potential (to monitor the anaerobic conditions) daily with the respective electrodes connected to a $\mathrm{pH}$ meter data-processing unit (model 713; Metrohm, Herisau, Switzerland). For the determination of VFA, $1.8 \mathrm{ml}$ of the fermenter fluid samples was stabilised with $0.2 \mathrm{ml}$ of a $46 \mathrm{mM}-\mathrm{HgCl}_{2}$ solution and frozen until analysis by $\mathrm{GC}$ (GC Star 3400 CX; Varian, Sugarland, TX, USA) as outlined by Tangerman \& Nagengast (1996). Counts of ciliate protozoa (entodiniomorphs and holotrichs) and bacteria were obtained daily with Bürker counting chambers $\left(0.1 \mathrm{~mm}\right.$ and $0.02 \mathrm{~mm}$ depth, respectively; Blau Brand ${ }^{\circledR}$, Wertheim, Germany). Fermentation gases were collected over $24 \mathrm{~h}$ in gas-tight bags (TECOBAG 81; Tesseraux Container $\mathrm{GmbH}$, Bürstadt, Germany) connected to the fermenters. The fermentation gases were collected completely by flushing the Rusitec system with gaseous $\mathrm{N}_{2}$ before uncoupling the bags from the fermenters. Fermentation gases were analysed for the concentrations of $\mathrm{CH}_{4}, \mathrm{H}_{2}$ 
and $\mathrm{CO}_{2}$ by a Hewlett Packard gas chromatograph (model 5890 Series II; Avondale, PA, USA) equipped with a flame ionisation detector, a thermal conductivity detector and a Carboxen-1000 column (mesh size 60/80; Fluka Chemie AG). The volume of the fermentation gases collected was quantified by pressing the gas into a closed tube filled with water and measuring the amount of water displaced. Substrates and substrate residues after $48 \mathrm{~h}$ of incubation were lyophilised and analysed for the amounts of DM, total ash, diethyl ether extract (only the substrates) and $\mathrm{N}$ (Dumas method, Leco-Analyser Type FP-2000; Leco Corporation, St Joseph, MI, USA), following standard procedures (Naumann \& Bassler, 1997). Crude protein was calculated as $6.25 \times \mathrm{N}$. Contents of neutral-detergent fibre (NDF) were analysed after incubation with $\alpha$-amylase (Termamyl 120L, Type S; Novo Nodirsk A/S, Bagsværd, Denmark), but without sodium sulfite, according to the protocol of Naumann \& Bassler (1997). Non-NDF carbohydrates were defined as the organic matter (OM) not incorporated in diethyl ether extract, crude protein, and NDF. A hydrogen balance, comprising $\mathrm{H}_{2}$ produced, utilised and recovered, was calculated by the equations of Demeyer (1991) considering VFA and $\mathrm{CH}_{4}$.

\section{Quantification of the methanogens}

The quantification of the $\mathrm{CH}_{4}$-producing archaea was carried out with the fluorescence in situ hybridisation technique, according to the laboratory manual of Stahl et al. (1995) with modifications briefly described by Machmüller et al. (2003). The fluorescence in situ hybridisation technique is based on the hybridisation of specific oligonucleotide probes complementary to the ribosomal RNA of the target microbes and can now routinely be used to identify and quantify microbes without cultural isolation. Based on Lin et al. (1997), five 16S rRNA oligonucleotide probes (Microsynth $\mathrm{GmbH}$, Balgach, Switzerland) were used, one domain-specific probe targeting all methanogens (S-S-Arc-0915-a-A-20) and four order-specific probes, targeting Methanococcales (S-F-Mcoc-1109-a-A-20), Methanosarcinales (S-O-Msar-0860-a-A-21), Methanomicrobiales (S-O-Mmic-1200-a-A-21) and Methanobacteriales (S-F-Mbac-0310-a-A-22). While the probe Arc-0915 has been described by Stahl \& Amann (1991), the four probes targeting the different methanogenic orders were designed and found to be specific for the respective target methanogens by Raskin et al. (1994). The hybridisation temperatures for the respective probes were $56^{\circ} \mathrm{C}$ for Arc$0915,55^{\circ} \mathrm{C}$ for Mcoc- $1109,60^{\circ} \mathrm{C}$ for Msar- $0860,53^{\circ} \mathrm{C}$ for Mmic-1200 and $57^{\circ} \mathrm{C}$ for Mbac-0310. Samples were viewed with an epifluorescence microscope (BX-60; Olympus Optical AG, Volketswil, Switzerland). Images of the fluorescent signals were taken with a $3 \mathrm{CCD}$ colour video camera (DXC-950P; Sony Corporation, Tokyo, Japan) and counted automatically with a software program (analySIS, version 3.1; Soft Imagine System GmbH, Uster, Switzerland). Quantifications of the archaea and the different methanogenic orders were done for the incubation days 10 and 15, which in the following are attributed to the two sub-periods $\mathrm{P} 1$ and $\mathrm{P} 2$, respectively.

\section{Calculations and statistical analysis}

Two statistical models were applied to analyse the variance of the data in the present experiment. Model 1 was based on the mixed procedure of the SAS program (version 8.2; SAS Institute Inc., Cary, NC, USA) with random and repeated statements as recommended by Littell et al. (1998). This model was applied to all data to evaluate the effects of treatment, sub-periods (P1 and P2), and the interaction among them. Additionally, experimental run was included in the model. Model 2 evaluated data for P1 (days 6 to 10) and P2 (days 11 to 15) separately with the general linear model procedure of SAS, regarding dietary treatment and experimental run as effects. All multiple comparisons among means were carried out with the Tukey method. In both models daily observations for each fermenter were averaged within each sub-period (P1 and P2). In all calculations treatment was the main effect and the sub-periods were considered as repeated observations obtained from the same fermenter. The subsequent experimental periods were considered as a blocking factor in the experimental design. Data are presented separately in the Tables for days 6 to 10 (P1) and days 11 to 15 (P2) whenever the group of traits showed some significant interactions in model 1.

\section{Results}

Effects of medium-chain fatty acids on fermentation gases

$\mathrm{CH}_{4}$ emission was depressed $(P<0.001)$ by MCFA mixtures containing $\mathrm{C}_{12}$ in proportions of $40 \%$ or more (Table 2). The highest $\mathrm{CH}_{4}$-suppressing effect compared with the unsupplemented control was obtained with $\mathrm{C}_{12}: \mathrm{C}_{14}$ in a $4: 1$ ratio (decline of $70 \%$ ), followed by ratios of $3: 2,2 \cdot 5: 2 \cdot 5,5: 0$, and $2: 3$ (declines of $60,48,43$ and $32 \%$, respectively) for days 6 to 15 (Table 2). $\mathrm{CH}_{4}$ release over $25 \mathrm{~d}$ (Fig. 1) showed that stable conditions were achieved from day 6 onwards. Differences developed among treatments were widely consistent up to day 21 , after which irregular developments occurred. The gaseous emission of $\mathrm{CO}_{2}$ was affected $(P<0.05)$ by the MCFA treatments but comparisons among means showed no specific significant differences. The overall average value for the $\mathrm{CO}_{2}$ emission was $66.5 \mathrm{mmol} / \mathrm{l}$. The amount of $\mathrm{H}_{2}$ in the gaseous phase was increased $(P<0 \cdot 001)$ by the supply of those MCFA mixtures that were high in $\mathrm{C}_{12}$ proportion, whereas the MCFA mixtures low in $\mathrm{C}_{12}$ proportion had smaller effects relative to the control treatment. However, a significant increase in $\mathrm{H}_{2}$ release compared with control was achieved only with $\mathrm{C}_{12}: \mathrm{C}_{14}$ in a $4: 1$ ratio, leading to an increase in the amount of $\mathrm{H}_{2}$ found in the gaseous phase by nearly 12 -fold. The calculated total amounts of $\mathrm{H}_{2}$ produced from various $\mathrm{H}_{2}$-producing processes did not differ significantly between the individual MCFA treatments. Compared with control, lower $(P<0 \cdot 001)$ values for $\mathrm{H}_{2}$ utilised and recovered were found with $\mathrm{C}_{12}: \mathrm{C}_{14}$ ratios of $5: 0,4: 1,3: 2,2 \cdot 5: 2 \cdot 5$ and $2: 3$, thus being affected inversely to the gaseous $\mathrm{H}_{2}$ release measured. The lowest $\mathrm{H}_{2}$ recovery rate was found with the $\mathrm{C}_{12}: \mathrm{C}_{14}$ ratio of $3: 2$. This rate was lower by $22.5 \%$ than that found in the unsupplemented control. There were no significant 


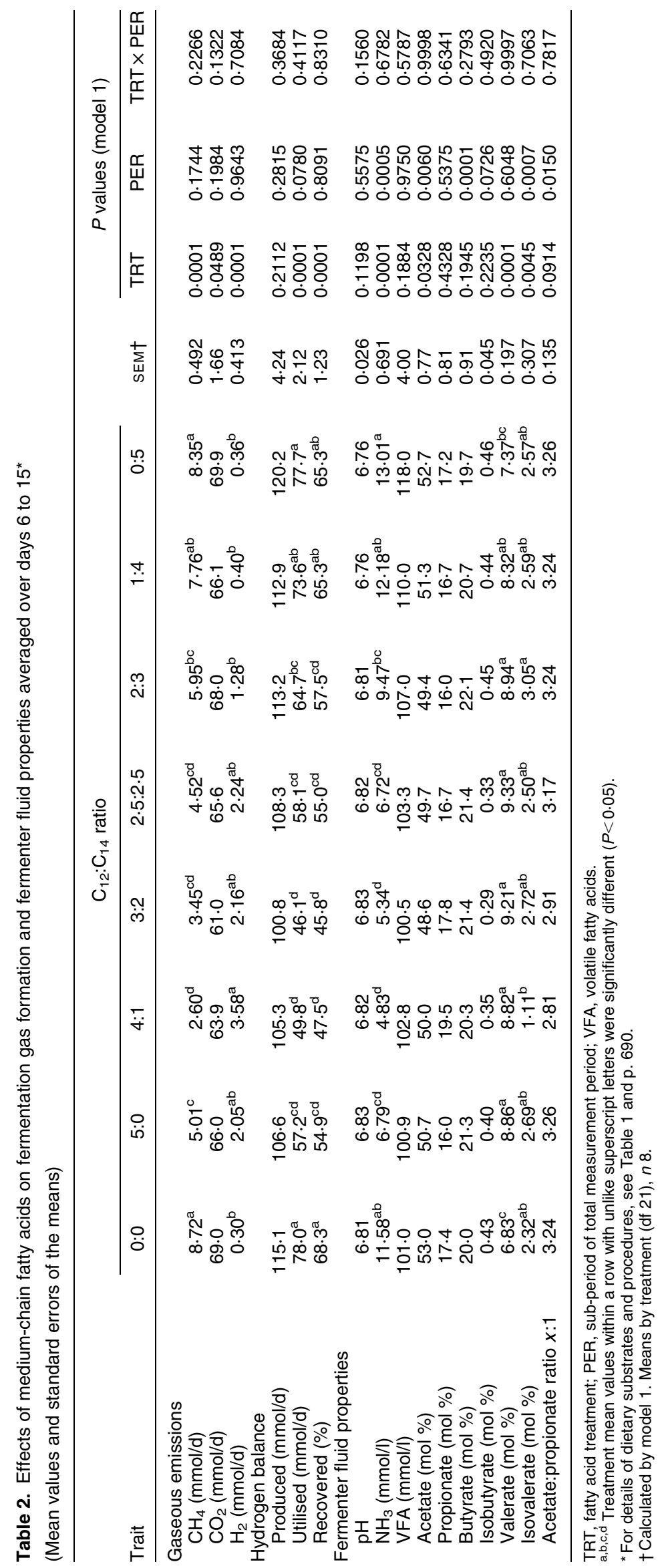




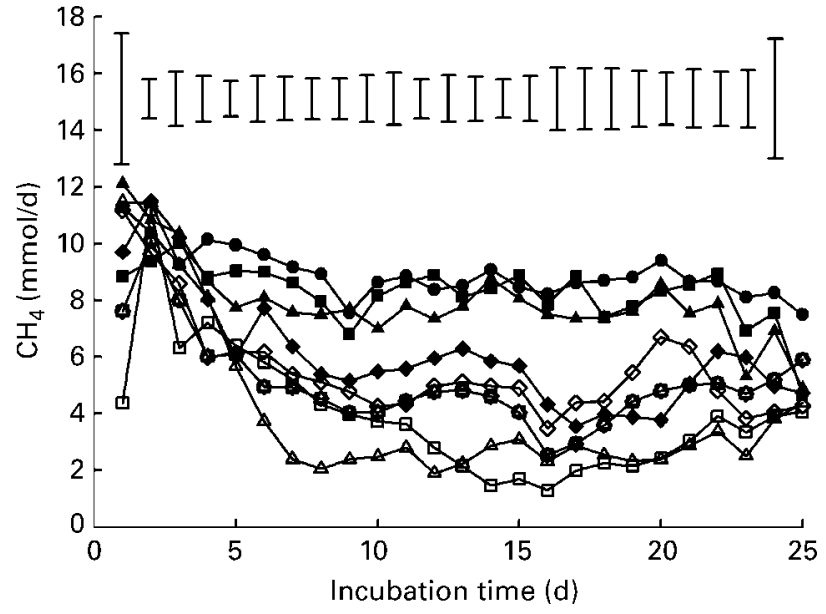

Fig. 1. In vitro $\mathrm{CH}_{4}$ release $(\mathrm{mmol} / \mathrm{d})$ from fermenter fluid, when incubating a control diet $(-\bullet-)$ and diets supplemented with mixtures of $\mathrm{C}_{12}$ and $\mathrm{C}_{14}$ in ratios of $0: 5(-\mathbf{-}-), 1: 4(-\boldsymbol{\Delta}-), 2: 3(-\boldsymbol{-})$,

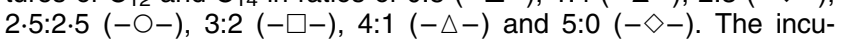
bation period was $25 \mathrm{~d}$ (days 1 to $15, n 4$; days 16 to $25, n 2$ ). Mean values are shown, with vertical bars representing standard errors of the mean.

interactions of treatment and sub-period in gaseous emissions and $\mathrm{H}_{2}$ balance.

\section{Effects of medium-chain fatty acids on microbial counts}

The MCFA treatments affected the ruminal microbial populations differently (Table 3 ). Total archaeal counts were affected by the MCFA supply in both sub-periods $(P<0.001)$. While in $\mathrm{P} 1$ archaeal counts were depressed $(P<0.05)$ by $\mathrm{C}_{12}: \mathrm{C}_{14}$ ratios of $5: 0,4: 1$ and $3: 2$ with decreases of 34,61 and $47 \%$ relative to the control, in $\mathrm{P} 2$ only the 4:1 and 3:2 ratios led to a significant decrease (57 and $47 \%$, respectively). Generally, in P2 total numbers of archaea were lower $(P<0.001)$ compared with $\mathrm{P} 1$, and interactions with the MCFA treatment occurred $(P<0 \cdot 05)$. All individual methanogenic orders, except Methanococcales, were significantly suppressed by the effective MCFA treatments. However, the four orders were affected to a different extent as a result of the MCFA supplementation, thus leading to changes in the population composition of the archaea. Out of all MCFA treatments, the counts of Methanobacteriales were decreased most with the $\mathrm{C}_{12}: \mathrm{C}_{14}$ ratio of $4: 1$ ( -46 and $-59 \%$ compared with the control in $\mathrm{P} 1$ and $\mathrm{P} 2$, respectively). For the counts of Methanomicrobiales similar effects were found, but here counts were significantly lower with this ratio compared with counts found with a $\mathrm{C}_{12}: \mathrm{C}_{14}$ ratio of $0: 5$. The counts of Methanosarcinales were lowest in P1 with the 4:1 treatment, followed by the $\mathrm{C}_{12}: \mathrm{C}_{14}$ ratios 5:0 and $3: 2$, all of them significantly different from the counts in the control. In P2 the largest decrease $(P<0.001)$ in counts of Methanosarcinales compared with the counts found in the control was observed with $\mathrm{C}_{12}: \mathrm{C}_{14}$ ratios of $3: 2,4: 1$ and $2 \cdot 5: 2 \cdot 5(-67,-64$ and $-56 \%$, respectively). Regarding the proportions of the different methanogenic orders (data not shown), Methanococcales was found to increase $(P<0.05)$ by up to
$17.2 \%\left(\mathrm{C}_{12}: \mathrm{C}_{14}\right.$ ratio of $\left.4: 1 ; \mathrm{P} 1\right)$ relative to control and Methanosarcinales to decrease $(P<0.05)$ by up to $11.2 \%$ $\left(\mathrm{C}_{12}: \mathrm{C}_{14}\right.$ ratio of $\left.5: 0 ; \mathrm{P} 1\right)$ and $9.4 \%\left(\mathrm{C}_{12}: \mathrm{C}_{14}\right.$ ratio of $3: 2$; P2). Proportions of Methanobacteriales and Methanomicrobiales were not significantly affected due to any MCFA supplementation.

Bacterial counts were not affected as a result of the MCFA treatments and amounted to $2.7 \times 10^{9} / \mathrm{ml}$ and $2.2 \times 10^{9} / \mathrm{ml}$ in the sub-periods $\mathrm{P} 1$ and $\mathrm{P} 2$, respectively, across all treatments. The same was found in the extended periods of days 16 to 25 with an average count of $2.1 \times 10^{9}$ bacteria/ml. Counts of total ciliate protozoa (data not shown), entodiniomorphs and holotrichs were significantly affected in P1 due to the MCFA treatment. This effect was not significant in $\mathrm{P} 2$. However, complete defaunation took place when supplying $\mathrm{C}_{12}: \mathrm{C}_{14}$ in ratios of $4: 1,3: 2,2 \cdot 5: 2 \cdot 5$ and $2: 3$ from day 7 onwards, resulting in the low average protozoal counts in P1. Interactions between the MCFA treatments and sub-periods occurred for both entodiniomorph $(P<0.001)$ and holotrich $(P<0.01)$ ciliate protozoal counts. In the unsupplemented control, no holotrich ciliate protozoa were found in the period of days 16 to 25 , whereas entodiniomorph ciliate protozoa were present until day 25 with counts of $0.29 \times 10^{3} / \mathrm{ml}$ on the last day.

\section{Effects of medium-chain fatty acids on fermenter fluid properties}

Supplementation with mixtures of $\mathrm{C}_{12}$ and $\mathrm{C}_{14}$ did not alter fermenter fluid $\mathrm{pH}$, which was 6.8 on average across all treatments during the whole measurement time (Table 2). Redox potential (data not shown) did not differ among MCFA treatments and averaged -323 and $-320 \mathrm{mV}$ in $\mathrm{P} 1$ and P2, respectively. Compared with the unsupplemented control, $\mathrm{NH}_{3}$ concentration in fermenter fluid was depressed $(P<0.001)$ due to the supplementation of $\mathrm{C}_{12}: \mathrm{C}_{14}$ in ratios of 5:0, 4:1, 3:2 and $2 \cdot 5: 2 \cdot 5$, with the highest decreases of 58 and $54 \%$ found with the ratios $4: 1$ and $3: 2$, respectively. Mixtures high in $\mathrm{C}_{14}$ proportions did not decrease $\mathrm{NH}_{3}$ concentration. No significant effects of MCFA treatments were found in the concentration of total VFA (mean value $106.7 \mathrm{mmol} / \mathrm{l}$ ) and in the molar proportions of propionate, butyrate and isobutyrate (mean values 17,21 and $0.4 \%$, respectively) during the measurement period of $15 \mathrm{~d}$. The molar proportion of acetate was affected by the MCFA treatment $(P<0.05)$, but comparison among means did not show specific significant differences (mean value of acetate, $52 \%$ of the total VFA). The molar proportion of valerate was enhanced $(P<0.001)$ with each MCFA treatment, except for the treatment with $\mathrm{C}_{14}$ supplied alone. The proportion of isovalerate was also affected $(P<0 \cdot 01)$ because of the fatty acid treatments but not in a systematic way. The acetate:propionate ratio remained unaffected and amounted to $3 \cdot 1$ on average over all treatments. Treatment effects on fermenter fluid properties did not depend on sub-period, and in the extended period from days 16 to $25, \mathrm{pH}, \mathrm{NH}_{3}$ concentration, and VFA concentrations and composition showed the same trends as in the two sub-periods P1 and P2 (data not shown). 


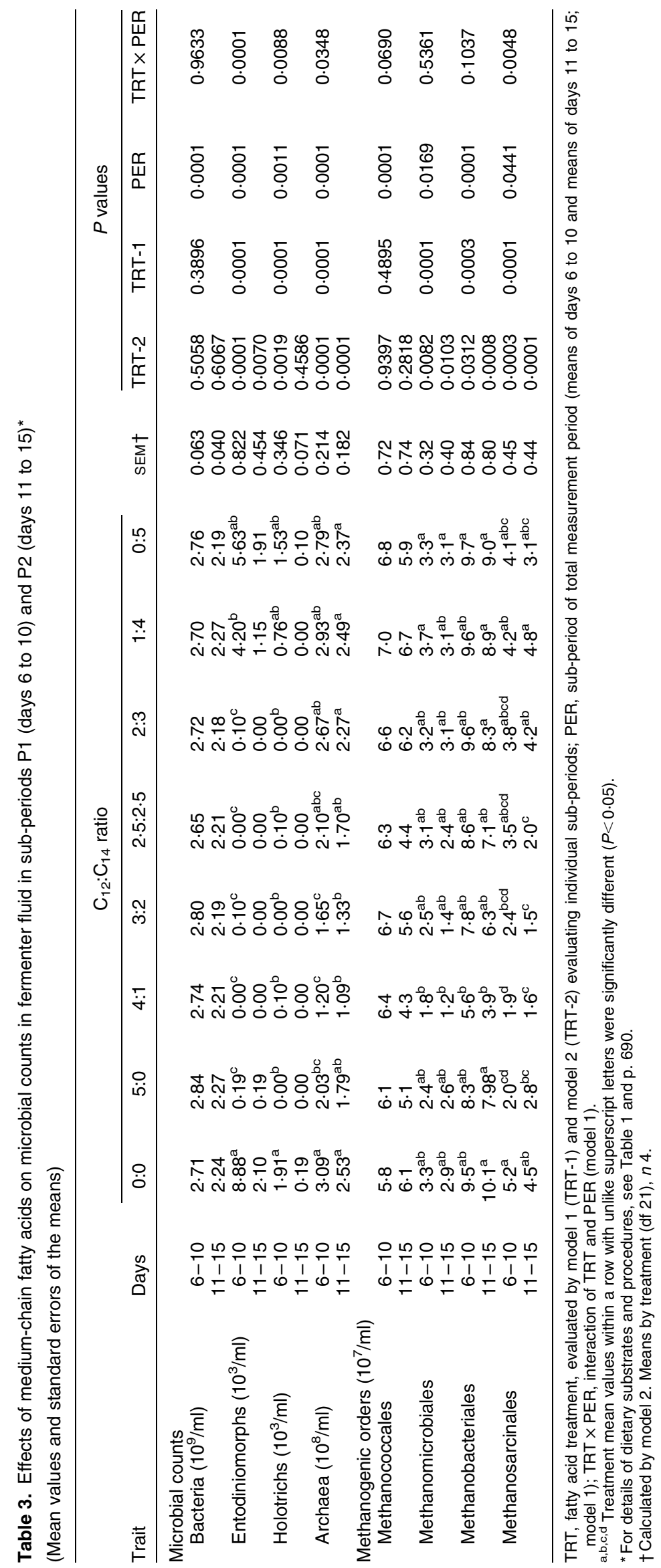




\section{Effects of medium-chain fatty acids on nutrient degradation}

The apparent degree of OM degradation was decreased $(P<0.001)$ by the MCFA treatment in P1 (Table 4$)$. In $\mathrm{P} 2$, differences to the control became insignificant in most MCFA treatments, except for the $\mathrm{C}_{12}: \mathrm{C}_{14}$ ratio of $3: 2(-9 \%)$. Interactions between the MCFA treatment and sub-periods $(P<0.05)$ also occurred for this trait. Compared with the unsupplemented control, the apparent rate of crude protein degradation was decreased $(P<0.001)$ by 13 , 10 and $10 \%$ in $\mathrm{P} 1$ with treatments containing $\mathrm{C}_{12}$ and $\mathrm{C}_{14}$ in ratios of $4: 1,3: 2$ and $2 \cdot 5: 2 \cdot 5$, respectively. In $\mathrm{P} 2$, crude protein degradation was decreased $(-12 \% ; P<0.01)$ with the 3:2 treatment. The apparent degree of NDF degradation was decreased $(P<0 \cdot 001)$ due to the supplementation of all fatty acid mixtures in $\mathrm{P} 1$, except for the treatment with $\mathrm{C}_{14}$ only. In P2 no effect of MCFA supplementation occurred. $\mathrm{CH}_{4}$ release related to the amount of apparently degraded OM was decreased $(P<0.001)$ in both sub-periods with all the $\mathrm{C}_{12}: \mathrm{C}_{14}$ treatments except for $1: 4$ and $\mathrm{C}_{14}$ alone. $\mathrm{CH}_{4}$ release related to the amount of apparently degraded NDF was affected by the MCFA supplementation in P1 $(P<0.01)$ as well as in P2 $(P<0.001)$. However, compared with the unsupplemented control, only the $\mathrm{C}_{12}: \mathrm{C}_{14}$ ratio of 4:1 decreased $\mathrm{CH}_{4}$ per unit of NDF degraded (48\%; $P<0.01)$ in $\mathrm{P} 1$. In $\mathrm{P} 2$, on the other hand, the treatments with $\mathrm{C}_{12}: \mathrm{C}_{14}$ in ratios of 5:0, 4:1, 3:2 and 2.5:2.5 affected this trait (decreases of $39,59,57$ and $35 \%$, respectively; $P<0 \cdot 001)$.

\section{Discussion}

\section{Suitability of the techniques used}

One major purpose of the present study was to confirm previous short-term in vitro findings (Soliva et al. $2003 \mathrm{~b}$ ) on the interactions of the two MCFA $\mathrm{C}_{12}$ and $\mathrm{C}_{14}$ in suppressing ruminal methanogenesis; results that were found in the absence of feed particles. Harfoot et al. (1974) showed that the presence of feed particles may diminish the efficacy of MCFA since it decreases the proportion of fatty acids attached to ruminal microbes, a factor crucial for the inhibitory effect of MCFA on methanogens (Henderson, 1973). In the present study, a concentrate-based feed substrate was used, since Machmüller et al. (2003) showed a more pronounced inhibition of total-tract $\mathrm{CH}_{4}$ release in sheep fed on a concentratebased diet supplemented with $\mathrm{C}_{14}$ rather than when fed a forage-based diet. The incubation period of $10 \mathrm{~d}$ applied previously in Rusitec experiments was extended to $15 \mathrm{~d}$ in the present study, and, for some variables, to $25 \mathrm{~d}$. Fermentation parameters such as $\mathrm{pH}$, bacterial counts and redox potential were consistent for at least 15 to $20 \mathrm{~d}$. In all fermenters subjected to the MCFA unsupplemented control, there were still entodiniomorph ciliate protozoa present on day 25. Most treatment effects did not change between sub-periods. This shows that the Rusitec system used was appropriate to investigate a prolonged incubation time and also that the commonly used measurement period of days 6 to 10 satisfactorily reflected most treatment effects.
Previous assumptions of Raskin et al. (1994) and Soliva et al. (2003b) that the four hybridisation probes chosen to quantify distinct taxonomic orders of methanogens cover all methanogens occurring in the rumen were confirmed. Summing the counts of all methanogenic orders on days 10 and 15 across all treatments accounted for 97 (SD 16) and 98 (SD 6) \%, respectively, of total archaea quantified with the Arc-0915 nucleotide probe. The methanogenic order that is most abundant, however, seems to vary widely among different studies. In the study of Lin et al. (1997), Methanobacteriales had the highest proportion of all orders in steers, cows and goats, whereas Methanomicrobiales predominated in sheep. In our previous investigations with sheep (Machmüller et al. 2003) and with ruminal fluid of a donor cow (Soliva et al. 2003b), Methanococcales dominated, while in the present study Methanobacteriales were most abundant, followed by Methanococcales (Table 3).

\section{Effects on ruminal methanogenesis}

MCFA are known to have the potential to suppress ruminal $\mathrm{CH}_{4}$ formation (for example, Blaxter \& Czerkawski, 1966). In vitro, Dohme et al. (2001a) identified $\mathrm{C}_{12}$ and $\mathrm{C}_{14}$ as the only two MCFA being effective in suppressing ruminal $\mathrm{CH}_{4}$ formation and methanogens. However, although $\mathrm{C}_{12}$ supplied alone suppressed $\mathrm{CH}_{4}$ release by $43 \%$ in the present study, $\mathrm{C}_{14}$ did not affect $\mathrm{CH}_{4}$ release at any time during the whole measurement period. Blaxter \& Czerkawski (1966) demonstrated that non-esterified $\mathrm{C}_{12}$ is more potent in inhibiting $\mathrm{CH}_{4}$ release than $\mathrm{C}_{14}$ in sheep, and there are two studies, one in vitro (Soliva et al. 2003b) and another in vivo (Dohme et al. 2001b), in which $\mathrm{C}_{14}$ was ineffective. In contrast, others (Dohme et al. 2001a; Machmüller et al. 2003) showed in vitro and in vivo that $\mathrm{C}_{14}$ alone can be effective in inhibiting methanogenesis. Overall, the efficacy of $\mathrm{C}_{14}$ seems variable and may depend on a combination of factors such as the dietary proportion of $\mathrm{C}_{14}$, being low in the study of Dohme et al. (2001b), the composition of the basal diet (Machmüller et al. 2003), the proportion of fermentable matter shifted from the rumen to the hindgut and, in case of in vitro studies, the origin of ruminal fluid (sheep or cattle).

Culture studies with granular sludge have indicated that mixtures of non-esterified $\mathrm{C}_{12}$ and $\mathrm{C}_{14}$ might be more efficient in inhibiting methanogenesis than one of these fatty acids alone (Koster \& Cramer, 1987). Incubating ruminal fluid and MCFA for $24 \mathrm{~h}$ in vitro (Soliva et al. 2003b) neither proved nor disproved a synergistic effect of mixtures of $\mathrm{C}_{12}$ and $\mathrm{C}_{14}$ on ruminal $\mathrm{CH}_{4}$ production since the sole supply of $\mathrm{C}_{12}$ nearly abolished $\mathrm{CH}_{4}$ formation. The slope of the regression curve in the in vitro study of Soliva et al. (2003b), however, suggested a certain synergistic effect between the two MCFA. In the present in vitro study, the synergistic effect between $\mathrm{C}_{12}$ and $\mathrm{C}_{14}$ in suppressing $\mathrm{CH}_{4}$ emission was clearly demonstrated. The use of the $\mathrm{C}_{12}: \mathrm{C}_{14}$ ratios of $4: 1,3: 2$ and $2 \cdot 5: 2 \cdot 5$ resulted in a more pronounced $\mathrm{CH}_{4}$-suppressing effect than the supply of $\mathrm{C}_{12}$ alone. Coconut oil and palm-kernel oil, feedstuffs rich in MCFA, have $\mathrm{C}_{12}: \mathrm{C}_{14}$ ratios of 2.6:1.0 to 3:1, which is in the range of the most efficient mixture of $\mathrm{C}_{12}$ 


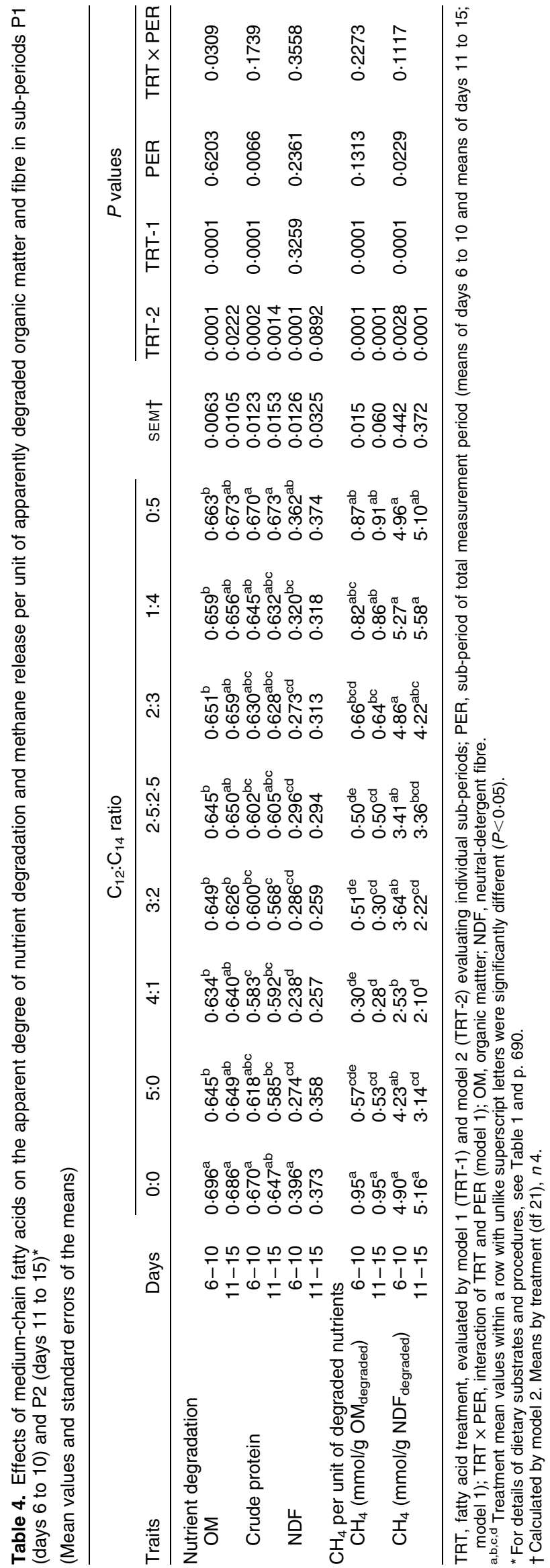


and $\mathrm{C}_{14}$ used in the present study, and which explains the high efficacy of these oils in suppressing $\mathrm{CH}_{4}$ formation in vitro (Dong et al. 1997; Dohme et al. 2000) and in vivo (Machmüller \& Kreuzer, 1999).

In the present study, free $\mathrm{H}_{2}$ accumulated in treatments with high $\mathrm{CH}_{4}$-suppressing effects (particularly with a $\mathrm{C}_{12}: \mathrm{C}_{14}$ ratio of $4: 1$ ). This is consistent with previous Rusitec-derived results (Machmüller et al. 2002) where MCFA supplementation significantly increased the amount of $\mathrm{H}_{2}$ in the gaseous phase. This accumulation probably resulted from a persistent $\mathrm{H}_{2}$ production of ruminal microbes while $\mathrm{CH}_{4}$ formation, as an $\mathrm{H}_{2}$ - and $\mathrm{CO}_{2}$-consuming process, was suppressed. As seen in previous studies (Machmüller et al. 1998, 2002), the accumulation of $\mathrm{H}_{2}$ was not stoichiometric with the inhibition of $\mathrm{CH}_{4}$ formation, illustrating that an increasing amount of $\mathrm{H}_{2}$ produced must have been used elsewhere. Other possible $\mathrm{H}_{2}$-consuming processes are, for instance, reductive acetogenesis (Van Nevel \& Demeyer, 1995; Le Van et al. 1998) and propionate formation, which is known for its inverse relationship to $\mathrm{CH}_{4}$ formation (Whitelaw et al. 1984). However, neither VFA was correspondingly affected in the present study. Propionate production requires interactions between microbial species that produce succinate, an $\mathrm{H}_{2}$-demanding process, and other microbial species that decarboxylate succinate to propionate (Wolin et al. 1997). Since an accumulation of succinate in the rumen is improbable (Blackburn \& Hungate, 1963), it might be possible that some of the succinate-producing microbes were inhibited by certain MCFA treatments. Finally, $\mathrm{H}_{2}$ could also have been utilised for the reduction of sulfate to sulfides (Morvan et al. 1996; Hino \& Asanuma, 2003), but this product was not determined in the present study.

\section{Effects on ruminal microbial populations}

It is well documented that MCFA have the potential to adversely affect ruminal ciliate protozoa, several bacterial species and methanogens (Henderson, 1973; Matsumoto et al. 1991; Dohme et al. 2001a; Soliva et al. 2003b). Supplementing $46 \mathrm{~g} \mathrm{C}_{12}$ or $\mathrm{C}_{14} / \mathrm{kg}$ total substrate in vitro suppressed ciliate protozoal counts only with $\mathrm{C}_{12}$ but not with $\mathrm{C}_{14}$ (Dohme et al. 2001a). Likewise, in the present study neither entodiniomorph nor holotrich ciliate protozoa were affected by the supplementation of $\mathrm{C}_{14}$ alone or a $\mathrm{C}_{12}: \mathrm{C}_{14}$ ratio of 1:4. All other treatments decreased counts of entodiniomorph as well as holotrich ciliate protozoa in the first sub-period (days 6 to 10), and all these treatments, except $\mathrm{C}_{12}$ alone, resulted in a complete defaunation of the fermenter fluid from experimental day 7 onwards. Defaunation, or a large decrease in the ciliate protozoal population, represents the loss of an important $\mathrm{H}_{2}$ donor for the ruminal archaea. Some archaea are associated with the ciliate protozoa ecto- and endosymbiotically (Finlay et al. 1994) and a decrease in ciliate protozoal counts might therefore decrease archaeal counts as well. However, limitations set by a lack of $\mathrm{H}_{2}$ were not the main reason for the suppressed $\mathrm{CH}_{4}$ formation found in those treatments, since gaseous $\mathrm{H}_{2}$ accumulated slightly in the treatments successful in suppressing $\mathrm{CH}_{4}$ formation. Furthermore, Dohme et al. (1999) showed that MCFA supplementation via coconut oil suppressed methanogenesis in both faunated and defaunated ruminal fluid. The significant decrease in ruminal fluid $\mathrm{NH}_{3}$ concentration and in apparent protein degradation found in treatments inhibiting ruminal ciliate protozoal population might be explained by the associated inhibition of the nutrient- and bacteriadegrading activity of the protozoa (Jouany, 1994). Similar to the findings of Dohme et al. (2001a), a suppression of the ciliate protozoal population did not result in the expected compensatory increase of the bacterial population (Jouany, 1994), which suggests that there might have been adverse MCFA effects on some bacterial species as well.

Corresponding to the variations found in $\mathrm{CH}_{4}$ release, clear effects of $\mathrm{C}_{12}$ on methanogenic counts, as described earlier (Dohme et al. 2001a; Soliva et al. 2003b), were found, and again the effects of $\mathrm{C}_{14}$ were smaller than that of $\mathrm{C}_{12}$ and not significant. In sheep, $\mathrm{C}_{14}$ did not clearly affect methanogenic counts either (Machmüller et al. 2003). Nevertheless, Henderson (1973) found more pronounced effects of $\mathrm{C}_{14}$ than of $\mathrm{C}_{12}$ on pure cultures of Methanobrevibacter ruminantium. Despite the uncertain effect of $\mathrm{C}_{14}$ alone, $\mathrm{C}_{12}$ and $\mathrm{C}_{14}$ acted synergistically in suppressing total archaeal counts when supplied in ratios of $4: 1$ and 3:2. In both sub-periods, the depressions were numerically larger with these ratios by about 40 and $20 \%$, respectively, than with $\mathrm{C}_{12}$ alone. This indicates a cooperative action of these two fatty acids and, therefore, a highly effective mechanism in inhibiting ruminal methanogens. Thus the present results confirm previous assumptions that MCFA are directly toxic to methanogens (Dong et al. 1997; Dohme et al. 1999). However, the mechanisms of how MCFA affect methanogens are still unclear. Koster \& Cramer (1987) suspected that $\mathrm{C}_{12}$ and $\mathrm{C}_{14}$ inhibit the metabolic activity of the methanogens by adsorption on to the microbial cell wall. Many studies were carried out investigating the effects of non-esterified MCFA and MCFA-monoacylglycerols on different microbes (Kabara \& Vrable, 1977; Thormar et al. 1987; Bergsson et al. 1998). According to these studies and other evidence (McLay et al. 2002), the cell membrane is thought to be the primary target of each agent and an enhanced inhibition would be the result of a multiple attack on the membrane. Lipophilic acids, including monolaurin $\left(\mathrm{C}_{12}\right.$ monoacylglycerol), are thought to disrupt the membrane integrity, which in turn interferes with membrane activities such as the transport of amino acids, resulting in cell starvation (Kabara, 1993). In the study of Bergsson et al. (2001), Gram-positive cocci were viewed by transmission electron microscopy after incubation with monocaprin for $30 \mathrm{~min}$. Disappearance of the plasma membrane and electron-transport granules was evident and the cell wall of some of the microbial cells appeared to be affected, which led to cell death.

Inconsistencies between $\mathrm{CH}_{4}$ formation and on methanogenic counts were smaller in the present study than found in other studies (Soliva et al. 2003a). Generally, these variations could be explained by different activities of the individual methanogenic cells (Soliva et al. 2003a,b) or by population changes resulting from the different susceptibility of individual methanogenic orders with differing $\mathrm{CH}_{4}$-producing activities to these MCFA. In the present 
study, certain shifts in the proportion of methanogenic orders caused by the MCFA treatments were found, as was also reported for a short-term incubation study (Soliva et al. 2003b) in which, as a result of the supplementation of $\mathrm{C}_{12}$ and mixtures of $\mathrm{C}_{12}$ and $\mathrm{C}_{14}$, Methanococcales were depressed to a larger extent than the other methanogenic orders. However, in the present study, the MCFA treatments predominantly depressed the counts of Methanosarcinales. Counts of Methanococcales were not significantly affected by any MCFA treatment and therefore increased in proportion to total archaea as all others were depressed, especially with $\mathrm{C}_{12}: \mathrm{C}_{14}$ ratios of $4: 1$ and $3: 2$. This change in archaeal population seems, however, not large enough to explain the particularly high $\mathrm{CH}_{4}$-suppressing effect of these two MCFA mixtures, particularly since the number of all archaeal orders declined numerically. Sharp et al. (1998) showed that representatives of the family Methanobacteriaceae are the methanogens most frequently associated with ciliate protozoa. In the present study, counts of Methanobacteriales were significantly suppressed due to the 4:1 MCFA treatment on incubation day 15 while ciliate protozoa had already been completely eliminated from the fermenters by day 10 .

\section{Effects on apparent organic matter and fibre degradation}

Lipids added to ruminant diets can greatly disturb ruminal fermentation by impairing the degradation of non-lipid energy sources (Jenkins, 1993). In particular, the ruminal digestion of structural carbohydrates can be decreased by $50 \%$ or more, even when less than $100 \mathrm{~g}$ fat $/ \mathrm{kg}$ are added (Jenkins \& Palmquist, 1984). A decrease in ruminal degradation of fibre, but not of $\mathrm{OM}$, due to $\mathrm{C}_{12}$ supplementation was also observed in the Rusitec studies of Dohme et al. (2001a) and Machmüller et al. (2002) within experimental periods of $10 \mathrm{~d} . \mathrm{C}_{14}$ was ineffective in that respect (Dohme et al. 2001a; present results) as was the case for fibre digestion in sheep fed a $\mathrm{C}_{14}$-supplemented diet (Machmüller et al. 2003). In the present study, the $\mathrm{C}_{12^{-}}$ alone treatment also caused a decreased fibre degradation, but only in the first sub-period, while incubations for 11 to $15 \mathrm{~d}$ mostly reversed these effects. The same was true for most mixtures of $\mathrm{C}_{12}$ and $\mathrm{C}_{14}$, once more underlining the presence of synergistic effects between both fatty acids. Initially decreased fibre degradation could have been caused by $\mathrm{H}_{2}$ accumulation, which might have inhibited activity of the fibre-degrading bacteria (Miller, 1995). However, these microbes must have adapted to $\mathrm{C}_{12}$ and $\mathrm{C}_{14}$ in contrast to other microbes such as the methanogens and the ciliate protozoa. This observation is of special importance since the degradation of plant cell walls by ruminants has a major economic value for developing countries and also for developed countries applying certain feeding strategies (Krause et al. 2003).

\section{Conclusions}

The present results demonstrate that the use of mixtures of $\mathrm{C}_{12}$ and $\mathrm{C}_{14}$ for the purpose of suppressing $\mathrm{CH}_{4}$ emission of domestic ruminants is superior to using either of these fatty acids alone. The most effective mixture of $\mathrm{C}_{12}$ and $\mathrm{C}_{14}$, when supplemented to a complete ruminant diet and incubated for up to $20 \mathrm{~d}$, was the $4: 1$ treatment, which decreased $\mathrm{CH}_{4}$ release by about $70 \%$. Additionally, this treatment only impaired ruminal fibre degradation at the beginning of the measurement period, demonstrating that the $\mathrm{CH}_{4}$-suppressing effect was not mainly caused by a depression in fibre degradation. This suggests that the desired effect of a lower methanogenesis persists while the unfavourable depression in ruminal fibre degradation seems to be reversible after some time. $A C_{12}: C_{14}$ ratio of $4: 1$ is reasonably close to that found in fats such as coconut oil and palm-kernel oil, thus explaining the high efficacy of such feedstuffs that are available in farm practice. Reasons for the high efficacy of the MCFA mixtures seem to be a synergism of the two fatty acids in suppressing the total archaeal population and, to a certain extent, the associated changes in composition of the methanogenic population and metabolic activity of the individual methanogens.

\section{Acknowledgements}

The authors owe thanks to Professors Braun and Wanner and their staff at the Faculty of Veterinary Medicine, University of Zurich, for giving access to the rumen-fistulated donor cow and for the analysis of the VFA. Thanks to B. Jörg for technical assistance with the Rusitec and the laboratory staff for the sample analyses. A. C. was supported by a scholarship of the Foundation for Polish Science.

\section{References}

Ababouch L, Chaibi A \& Busta FF (1992) Inhibition of bacterial spore growth by fatty acids and their sodium salts. J Food Protect 55, 980-984.

Abel HJ, Immig I \& Harmann E (2002) Effect of adding caprylic and capric acid to grass on fermentation characteristics during ensiling and in the artificial rumen system RUSITEC. Anim Feed Sci Technol 99, 65-72.

Bergsson G, Arnfinnsson J, Karlsson SM, Steingrimsson O \& Thormar H (1998) In vitro inactivation of Chlamydia trachomatis by fatty acids and monoglycerides. Antimicrob Agents Chemother 42, 2290-2294.

Bergsson G, Arnfinnsson J, Steingrimsson O \& Thormar H (2001) Killing of gram-positive cocci by fatty acids and monoglycerides. APMIS 109, 670-678.

Blackburn TH \& Hungate RE (1963) Succinic acid turnover and propionate production in the bovine rumen. Appl Microbiol 11, 132-135.

Blaxter KL \& Czerkawski J (1966) Modification of methane production of sheep by supplementation of its diet. J Sci Food Agric 17, 417-420.

Carro MP, Lebzien P \& Rohr K (1995) Effect of pore size of nylon bags and dilution rate on fermentation parameters in a semi-continuous artificial rumen. Small Rum Res 15, 113-119.

Czerkawski JW \& Breckenridge G (1977) Design and development of a long-term rumen simulation technique (RUSITEC). Br J Nutr 38, 317-384.

Demeyer DI (1991) Quantitative aspects of microbial metabolism in the rumen and hindgut. In Rumen Microbial Metabolism and Ruminant Digestion, pp. 217-237 [JP Jouany, editor]. Paris, France: INRA Editions. 
Dohme F, Machmüller A, Estermann BL, Pfister P, Wasserfallen A \& Kreuzer M (1999) The role of the rumen ciliate protozoa for methane suppression caused by coconut oil. Lett Appl Microbiol 29, 187-192.

Dohme F, Machmüller A, Wasserfallen A \& Kreuzer M (2000) Comparative efficiency of various fats rich in medium-chain fatty acids to suppress ruminal methanogenesis as measured with Rusitec. Can J Anim Sci 80, 473-482.

Dohme F, Machmüller A, Wasserfallen A \& Kreuzer M (2001a) Ruminal methanogenesis as influenced by individual fatty acids supplemented to complete ruminant diets. Lett Appl Microbiol 32, 47-51.

Dohme F, Sutter F, Machmüller A \& Kreuzer M (2001b) Methane formation and energy metabolism of lactating cows receiving individual medium-chain fatty acids. In Energy Metabolism in Animals. Proceedings of the 15th Symposium on Energy Metabolism in Animals, 2000, pp. 369-372 [A Chwalibog and K Jabobsen, editors]. Wageningen, The Netherlands: Pers Wageningen.

Dong Y, Bae HD, McAllister TA, Mathison GW \& Cheng K-J (1997) Lipid-induced depression of methane production and digestibility in the artificial rumen system (RUSITEC). Can $J$ Anim Sci 77, 269-278.

Finlay BJ, Esteban G, Clarke KJ, Williams AG, Embley TM \& Hirt RP (1994) Some rumen ciliates have endosymbiotic methanogens. FEMS Microbiol Lett 117, 157-162.

Harfoot CG, Crouchman ML, Noble RC \& Moore JH (1974) Competition between food particles and rumen bacteria in the uptake of long chain fatty acids and triglycerides. J Appl Bact 37, 633-641.

Henderson C (1973) The effect of fatty acids on pure cultures of rumen bacteria. J Agric Sci 81, 107-112.

Hino T \& Asanuma N (2003) Suppression of ruminal methanogenesis by decreasing the substrates available to methanogenic bacteria. Nutr Abstr Rev 73, 1-8.

Jenkins TC (1993) Lipid metabolism in the rumen. J Dairy Sci 76, $3851-3863$

Jenkins TC \& Palmquist DL (1984) Effect of fatty acids or calcium soaps on rumen and total nutrient digestibility of dairy rations. J Dairy Sci 67, 978-986.

Jouany JP (1994) Manipulation of microbial activity in the rumen. Arch Anim Nutr 46, 133-153.

Kabara JJ (1993) Medium-chain fatty acids and esters. In Antimicrobials in Foods, pp. 307-342 [PM Davidson and AL Branen, editors]. New York: Marcel Dekker.

Kabara JJ \& Vrable R (1977) Antimicrobial lipids: natural and synthetic fatty acids and monoglycerides. Lipids 12, 753-759.

Khalil MAK (2000) Atmospheric methane: an introduction. In Atmospheric Methane: Its Role in the Global Environment, pp. 1-8 [MAK Khali, editor]. Berlin, Germany: SpringerVerlag.

Koster IW \& Cramer A (1987) Inhibition of methanogenesis from acetate in granular sludge by long-chain fatty acids. Appl Environ Microbiol 53, 403-409.

Krause DO, Denman SE, Mackie RI, Morrison M, Rae AL, Attwood GT \& McSweeney CS (2003) Opportunities to improve fiber degradation in the rumen: microbiology, ecology, and genomics. FEMS Microbiol Rev 27, 663-693.

Le Van TD, Robinson LA, Ralph J, Greening RC, Smolenski WJ, Leedle JAZ \& Schaefer DM (1998) Assessment of reductive acetogenesis with indigenous ruminal bacterium populations and Acetitomaculum ruminis. Appl Environ Microbiol 64, 3429-3436.

Lin C, Raskin L \& Stahl DA (1997) Microbial community structure in gastrointestinal tracts of domestic animals: comparative analyses using rRNA-targeted oligonucleotide probes. FEMS Microbiol Ecol 22, 281-294.
Littell RC, Henry PR \& Ammerman CB (1998) Statistical analysis of repeated measures data using SAS procedures. J Anim Sci 76, 1216-1231.

Machmüller A \& Kreuzer M (1999) Methane suppression by coconut oil and associated effects on nutrient and energy balance in sheep. Can J Anim Sci 79, 65-72.

Machmüller A, Ossowski DA, Wanner M \& Kreuzer M (1998) Potential of various fatty feeds to reduce methane release from rumen fermentation in vitro (Rusitec). Anim Feed Sci Technol 71, 117-130.

Machmüller A, Soliva CR \& Kreuzer M (2002) In vitro ruminal methane suppression by lauric acid as influenced by dietary calcium. Can J Anim Sci 82, 233-239.

Machmüller A, Soliva CR \& Kreuzer M (2003) Methane-suppressing effect of myristic acid in sheep as affected by dietary calcium and forage proportion. Br J Nutr 90, 529-540.

Matsumoto M, Kobayashi T, Takenaka A \& Itabashi H (1991) Defaunation effects of medium-chain fatty acids and their derivatives on goat rumen protozoa. J Gen Appl Microbiol 37, 439-445.

McLay JC, Kennedy MJ, O'Rourke AL, Elliot RM \& Simmonds RS (2002) Inhibition of bacterial foodborne pathogens by the lactoperoxidase system in combination with monolaurin. Int $J$ Food Microbiol 73, 1-9.

Miller TL (1995) Ecology of methane production and hydrogen sink in the rumen. In Ruminant Physiology: Digestion, Metabolism, Growth and Reproduction, pp. 317-331 [W Engelhardt, G Breves, S Leonhard-Marek and D Giesecke, editors]. Berlin, Germany: Ferdinand Enke Verlag.

Morvan B, Bonnemoy F, Fonty G \& Gouet P (1996) Quantitative determination of $\mathrm{H}_{2}$-utilizing acetogenic and sulfate-reducing bacteria and methanogenic archaea from digestive tract of different mammals. Curr Microbiol 32, 129-133.

Naumann K \& Bassler R (1997) Die chemische Untersuchung von Futtermitteln. In Methodenbuch, 4th ed., vol. III, chapter 6.5.1, pp. 1-4. Darmstadt, Germany: VDLUFA-Verlag.

Raskin L, Stromley JM, Rittmann BE \& Stahl DA (1994) Groupspecific 16S rRNA hybridization probes to describe natural communities of methanogens. Appl Environ Microbiol 60, $1232-1240$

Sharp R, Ziemer CJ, Stern MD \& Stahl DA (1998) Taxon-specific associations between protozoal and methanogen populations in the rumen and a model rumen system. FEMS Microbiol Ecol 26, $71-78$.

Soliva CR, Hess HD, Meile L, Kreuzer M \& Machmüller A (2003a) Suppression of ruminal methanogenesis by dietary means: apparent inconsistency between methane release and counts of microbes involved in methanogenesis. Tropic Subtropic Agroecosyst 3, 209-213.

Soliva CR, Hindrichsen IK, Meile L, Kreuzer M \& Machmüller A (2003b) Effects of mixtures of lauric and myristic acid on rumen methanogens and methanogenesis in vitro. Lett Appl Microbiol 37, 35-39.

Stahl DA \& Amann R (1991) Development and application of nucleic acid probes. In Nucleic Acid Techniques in Bacterial Systematics, pp. 205-248 [E Stackebrandt and M Goodfellow, editors]. New York: John Wiley \& Sons Inc.

Stahl DA, Amann RI, Poulsen LK, Raskin L \& Capman WC (1995) Use of fluorescent probes for determinative microscopy of methanogenic archaea. In Archaea: Methanogens: A Laboratory Manual, pp. 111-121 [KR Sowers and HJ Schreier, editors]. New York: Cold Spring Harbor Laboratory Press.

Tangerman A \& Nagengast FM (1996) A gas chromatographic analysis of fecal short-chain fatty acids, using the direct injection method. Anal Biochem 236, 1-8.

Thormar H, Isaacs CE, Brown HR, Barshatzky MR \& Pessolano $\mathrm{T}$ (1987) Inactivation on enveloped viruses and killing of 
cells by fatty acids and monoglycerides. Antimicrob Agents Chemother 31, 27-31.

Van Nevel CJ \& Demeyer DI (1995) Feed additives and other interventions for decreasing methane emissions. In Biotechnology in Animal Feeds and Animal Feeding, pp. 329-349 [RJ Wallace and A Chesson, editors]. Weinheim, Germany: VCH. Whitelaw FG, Eadie JM, Bruce IA \& Shand WJ (1984) Methane formation in faunated and ciliate-free cattle and its relationship with rumen volatile fatty acid proportions. Br J Nutr 52, $261-275$.

Wolin MJ, Miller TL \& Stewart CS (1997) Microbe-microbe interactions. In The Rumen Microbial Ecosystem, pp. 467-491 [PN Hobson and CS Stewart, editors]. London: Chapman and Hall.

Wuebbles DJ \& Hayhoe K (2002) Atmospheric methane and global change. Earth-Sci Rev 57, 117-210. 